\title{
World Englishes and English Language Teaching: A pragmatic and humanistic approach
}

\section{Lenguas inglesas del mundo y la enseñanza del inglés: un enfoque pragmático y humanístico}

\section{Subrata Kumar Bhowmik ${ }^{1}$}

Citation / Para citar este artículo: Bhowmik, S. K. (2015). World Englishes and English Language Teaching: A Pragmatic and Humanistic Approach. Colomb. Appl. Linguist. J., 17(1), pp.142-157.

Received: 12-Aug-2014 / Accepted: 27-Apr-2015

DOI: http://dx.doi.org/10.14483/udistrital.jour.calj.2015.1.a10

\section{Abstract}

Seidlhofer (2005) describes the current status of English as an "unstable equilibrium." In many ways this analogy regarding the current state of affairs with English language teaching (ELT) is appropriate. Taking a World Englishes (WE) perspective, this paper presents various mismatches between teaching goals and objectives vis-à-vis the teaching and learning outcomes in ELT. The paper then makes the argument that in order for more successful English language teaching and learning to take place, a pragmatic and humanistic approach needs to be adopted. An outline of such an approach is discussed.

Keywords: ELT, a humanistic approach to ELT, a pragmatic approach to ELT, World Englishes

\section{Resumen}

Seidlhofer (2005) describe el estado actual de inglés como un "equilibrio inestable". En muchos sentidos, esta analogía con respecto a la situación actual con la enseñanza del idioma Inglés (ELT) es apropiado. Tomando una perspectiva de las lenguas inglesas del mundo (World Englishes), este trabajo presenta varios desajustes entre las metas y los objetivos en relación con los resultados de enseñanza y aprendizaje en la enseñanza ELT. En el documento se presenta, entonces, el argumento de que para que la enseñanza y el aprendizaje del idioma Inglés tengan lugar con más éxito, un enfoque pragmático y humanista debe ser adoptado. Se discute un esquema de este tipo de enfoque.

Palabras clave: ELT, enfoque humanístico a ELT, enfoque pargmático a ETL, lenguas inglesas del mundo

1 University of Calgary, Calgary, Canada. sbhowmik@ucalgary.ca 


\section{Introduction}

English language teaching has witnessed a major boom around the globe in recent times. The continuous spread of English has given rise to different varieties of English language, making it almost impossible to trace the norms for Standard English (SE) (e.g., Brutt-Griffler, 2002; Kachru, 1982; Lowenberg, 2000, pp. 69-73). As the proliferation of English education continues at our time, the variety of English to be considered as SE, the norms to be followed in English language pedagogy (Kachru, 1982, p. 49), and the materials to be used for English language teaching (ELT) curriculum are but only a few issues that constitute some of the most intriguing concerns in the field. Research shows that the global spread of English has significant bearing on ELT. Much of this bearing has manifested itself in the lack of a uniform target variety of English for instruction and the prevailing problems in setting suitable teaching goals and objectives commensurate to teaching and learning outcomes. In this paper, I take an exploratory approach to investigate these conundrums relating to ELT. Specifically, I look at problems that ELT faces in setting a uniform target variety for instruction; curriculum design and materials development; testing; and teacher training-areas that are absolutely crucial for any language pedagogy.

Prevalence of more than one standard variety of any given language may not be entirely unusual. This trend may hold true for various languages in the world such as Arabic, Chinese, French, Greek, and so on. Difficulties in setting a uniform standard variety while teaching these languages as a second or foreign language may parallel those in English. However, what separates the context of the teaching of English from other languages is English's status as the most high stake, most used, and most widespread language the world has ever known (Kachru \& Nelson, 1996, p. 71). Besides, the continuous spread of English worldwide has put it in a unique situation. For example, because of its spread over time, English has become more hybridized and diverse, a phenomenon captured by the term World Englishes. In such a milieu, it is natural that English language teaching at present is more challenging than ever before.
ELT in the twenty-first century encounters a myriad of problems. A closer look at them suggests that the root of many of these problems lies in the unprecedented global spread of English in the last few decades that has given rise to different varieties of English language. A brief explanation in this regard is in order. Different varieties of English mean that ELT can no longer afford to choose between only British or American English as the primary target variety for instruction. As the spread of English continues, nonnative-nonnative interactions have become more common than native-native and native-nonnative interactions (Lowenberg, 2000, p. 67). For instance, according to an estimate provided by Crystal (1997, cited in Graddol, 1997), in 1995 there were approximately 377 million people using English as their L1, while at the same time there were about 235 million people using English as their second language. Crystal (1997, cited in Graddol, 1999) notes that in 50 years (i.e., from 1995) this balance would shift significantly as the number of people using English as a second or foreign language would almost double. In fact, it is argued that at present, nonnative speakers of English have already outnumbered their native counterparts and that native speakers comprise only "a fifth or less" of world's total English users. (e.g., Lowenberg, 2000, p. 67).

In spite of this ever-widening spectrum of the English speaking population, ELT is still mostly controlled (i.e., determining the norms for teaching, designing syllabus, producing materials, and so on) by "native-speaking," inner-circle countries. ${ }^{2}$ Seidlhofer (2004) refers to this situation as an "unstable equilibrium" (p. 209). That is, while

2 It is worth noting that Kachru's concentric model distinctions between inner-, outer-, and expanding-circle are not absolute. There has been a great deal of criticism about this model. For example, Tripathi (1998) observes that this model assumes that there is uniformity of English language within each group of countries. But in reality, this notion is far from true. He further argues that great linguistic diversity exists within inner-circle (such as USA, Canada) as well as outer-circle (such as India, Pakistan) countries. Furthermore, Tripathi (1998) maintains that the concentric model cannot sufficiently explain the evolving nature of the linguistic changes within each circle. Although circles in their "connotational sense" could be expanded due to various external or internal forces, "...this happens regardless of the spatial order inner or outer" (p. 56). Australia and New Zealand, for instance, were included in inner-circle English in the past; similarly, there could be more inner-circle English countries in future. This happens due to the natural course of various (socio) linguistic phenomena. 
nonnative speakers have outnumbered their native counterparts, native speakers of English still enjoy the privileges of being "native." Native speakers, for instance, are entitled to getting "special status" (Graddol, 1999, p. 67) as well as various material and psychological benefits while using English in everyday life. After all, it is the inner-circle speakers who set the standard norms for English, get jobs that are meant only for "native speakers," get a raise or promotion at work just because they identify themselves as native speakers of English (e.g., Kirkpatrick, 2007). At pedagogical levels, the impacts of this phenomenon are quite pervasive too-inner-circle-oriented curriculum design and materials development that show little or no sensitivity to local contexts, developing tests that are incompatible with local teaching and learning goals and objectives, preference for native English speakers for English teaching positions, undue stress on learners for appropriating a particular variety of inner-circle English often disregarding more popular localized varieties are some examples in this connection (Canagarajah, 1999; Kirkpatrick, 2007; Phillipson, 1992). As one can see, ELT these days is characterized by numerous tensions on the part of both teachers and students. What is important to note here is that these factors not only impact teachers and learners but also the actual English language teaching practices (e.g., approaches and methods). At times, these impacts are so far reaching that they lead to failures and/or disruptions of English language teaching and learning goals (Canagarajah, 1999). Therefore, it is important to engage in deliberations on how WE issues permeate ELT.

In the following sections, I organize my discussions as follows: I first draw on issues relating to standards of English and how they have made it difficult for ELT practitioners to set a uniform target variety for ELT. As mentioned above, because there are so many varieties of English, encompassing inner-, outer-, and expanding-circle countries, there is always a conflict as to which variety should be used as a standard norm. Further, various ownershiprelated ideologies (i.e., ownership of English) make things more complicated in this regard. In the subsequent sections, I discuss the difficulties that ELT faces in curriculum design and materials development, testing, and teacher training. Finally,
I make it a point that a pragmatic and humanistic approach to ELT is necessary for a globalized world that is diverse and fast-changing.

\section{English in the twenty-first century- what are the standards?}

The global spread of English in the last few decades has caused an unprecedented growth of the language. What this means is that English has grown into a great many varieties. An important fact about the rise of different varieties of English is that they are not only limited to the outer- and expanding-circle countries, rather varieties of English are equally prevalent in inner-circle countries (Widdowson, 1994, p. 378). With so many existing varieties, maintaining standard norms for English to be used as a single reference point has always been a challenge for its users. The issue is particularly critical for practitioners of ELT since they need to set fixed standards for their teaching purposes. In the section below, I examine issues relating to SE that often intrigue ELT practitioners. The ownership of English, a related concept, also figures in the discussion. After all, standards are typically set by the "owners" of the language.

Widdowson (1994) problematizes the concept of standards and ownership of English. He suggests that language maintenance is a task that is not necessarily endowed upon a particular subset of people who are by default native speakers of the language. In fact, Widdowson argues that the responsibility of maintaining the standard rests upon all of those who speak/use the language. That is, he implicitly concedes that the ownership of the language belongs to all. But in reality the fact remains that inner-circle countries determine the standards of English. ELT courses modeled after inner-circle norms do not address local needs and preferences. Matsuda (2003), for example, maintains that when the English language that is taught in EFL/ESL follows inner-circle English, it may result in the neglect of local learners' linguistic needs, ignoring their education about the history and politics surrounding the English language, and the failure to empower learners with ownership of English (p. 721). 
What is more, the measures used to evaluate the standards vary across time and space. For instance, in Britain many people relate spelling errors to a non-standard variety of English. For others, it might be the lexical, grammatical, or phonological system. Widdowson (1994) distinguishes between two major functions of language: communal and communicative. While communal functions relate more to the conventions (such as spelling and accent) of a given language, communicative functions have more to do with communication among its users. According to Widdowson, it is at the level of communal function that the concept of "standard" becomes an issue as it allows its users to exclude those who do not follow the conventionsthe "standards" of English. It also allows the followers of the standard variety of English to wield power and prestige (Lowenberg, 2000) over those who do not belong to the "community" (see also Kachru, 1982, pp. 49-52 for an account of how the concept of "models" [roughly synonymous to "standards"] can be disadvantageous). In contrast, at the communicative level, the fact remains that as long as communication is accomplished, the English language remains fully functional. This is not to say, however, that the communal function of English should be considered unimportant.

As one can see, the ownership of English and the "standards" of the language are inseparably related. The concept of SE is relative to how the native speakers define the term to maintain its communal functions. As discussed above, no matter how important standards are for maintaining communal integrity, they may not simply serve any purpose in accomplishing communicative functions. In the current scenarios in which English language teaching and learning take place, it is the communicative function that matters the most to both learners and teachers (e.g., Alptekin, 2002; Rajagopalan, 2004). Since the main purpose of most English language education is to make learners communicatively competent, addressing the communal function of English, making students learn about the nuanced conventions or standards of the language may be a misfit in the long list of ELT goals and objectives.

This approach to English language teaching/ learning is in contradiction with the interests of most native speakers. One of the most commonly made arguments by native speakers is that a lack of standards allows a proliferation of what they label as deficit English. One may notice that this argument involves more material than practical considerations; it involves material stakes such as the control and ownership of English on the part of native speakers. An example to this end would help clarify this point: It is predominantly the native speakers who control, design, and produce the majority of ELT materials worldwide and provide themselves with a huge share of the ELT market (Kirkpatrick, 2007). Therefore, a complete control and ownership of English are of significant material interests to them. However, considering the volume of the global spread of English in the twenty-first century, restricting the language to native speakers is as impractical as it is inappropriate.

Indeed, pluricentricity is the theme of much of the work related to the spread of English in recent times. While Kachru's $(1982,1985)$ concentric model sets the tone for conceptualization of what is now popularly known as World Englishes (WE), the trend has moved on and continued to promote the importance of viewing English as a language of the world, owned by the peoples around the globe. Over the years, English has been "the most widely taught, read and spoken language the world has ever known" (Kachru \& Nelson, 1996, p. 71). While researchers recognize different varieties of English based on various linguistic levels such as vocabulary and grammar, and accent (Strevens, 1983; cited in Kachru \& Nelson, 1996), what binds it together is its common communicative goal. Indeed, helping learners develop communicative skills in English has been one of the primary teaching goals in ELT curricula. However, with so many different indigenous varieties of English (e.g., Indian English, Nigerian English, Singaporean English, etc.) coupled with conflicting learning needs for passing standardized English tests and communicating with different subsets of people, setting appropriate teaching goals in ELT and teaching communicative skills is not an easy task. A corollary of this has been a tremendous impetus for the codification of the characteristics of different varieties of English, which has resulted in new research agenda in WE. 
Efforts have been well underway to describe and codify varieties of English language spoken by nonnative speakers. Some of the notable projects in this area are: Jenkins' "Lingua Franca Core" (LFC) (Jenkins, 1998, 2002); work on English as a Lingua Franca Pragmatics by Blommaert and Verschueren (1991) and Spencer-Oatey (2000); and Seidlhofer's work on the description of lexico-grammatical issues of English as a Lingua Franca as part of the VOICE project at University of Vienna (Seidlhofer, 2002). Although different researchers may be in disagreement with each other over the meanings of the terms such as English as a Lingua Franca (ELF) or English as an International Language (EIL) (e.g., Jenkins, 2006), it must be kept in mind that they are intended to serve a common purpose- to underscore the importance of describing English used by nonnative speakers and to come up with a uniform reference point for English language used by outerand expanding-circle countries. Research in this area of English studies has increased exponentially in recent times (see Jenkins, 2006 for more) to signal a welcome shift from a monocentric approach to English to a pluricentric one. Interestingly, this shift of approach to English language studies is directly related to the issue of ownership of the English language. While a monocentric approach would give more power to the native speakers, their norms and ways of using English; pluricentricity, by contrast, is everyone's norm, everyone's usage. This invariably puts the custodians of English (to use Widdowson's, 1994 words), the native speakers, in a less powerful position with regard to the future course of the English language.

Graddol's (1997) observation regarding the ownership of English may be relevant at this point. In the overview of his book The Future of English, Graddol (1997) predicts "significant global trends - in economics, technology and culture..." (p. 2) that may transform the world in the twenty-first century and cause a new world order. Graddol further points out that ultimately the native speakers of English might be uncomfortable with the effects of these changes on the English language. Based upon various facts, trends, and ideas, Graddol's prediction has several implications regarding the status of English-most crucially, its ownership. Because the spread of English is occurring so fast and these days so many nonnative speakers use the language, the control over English may go into the hands of the nonnative speakers. Control here does not necessarily indicate hogging the language as a possession. The measure of control of English in this case is determined by the sheer number of people using the language. As mentioned earlier, nonnative speakers of English have already outnumbered their native counterparts. As a result, nonnative-nonnative interactions in English are far more common than native-nonnative interactions. This alone has significant implications relating to the concept of SE. For example, with the continuing rise of nonnative speakers of English and interactions among themselves, it is believed that English will be used more for its communicative functions (more in line with what is described above), leaving standards to be of less significance. In fact, the new "world order" might just compel them to forgo the purists' version of English for a more hybridized and "impure" version of "world English," known by terms such as ELF (English as a Lingua Franca) and EIL (English as an International Language).

That said, although several research projects are aimed at codifying different levels of ELF/EIL (e.g., Jenkins, 2006; Seidlhofer, 2004), it is by no means an easy task for various reasons. First, it is extremely difficult to come up with a uniform set of characteristics with so many varieties around. Second, it is also difficult to devise an objective set of principles of ELF/EIL for pedagogical purposes. The intelligibility principle (Levis, 2005), for example, has been a long-held reference point in the practice of pronunciation teaching, although it is widely believed that there is no single and universally-agreed-upon definition and measure of "intelligibility" in language teaching (Derwing E Munro, 2005; Jenkins, 2000). Finally, even if researchers in the field successfully come up with proper descriptions of the characteristics of ELF and EIL, in the end it is feared that it may only yield a set of prescriptive formulae for ELT, much like what native-speaking varieties of English have done over the years. This, of course, is contradictory to the spirit of a pluricentric view of WE in ELT.

In fact, it is true that the monocentric, "nativespeaker-oriented" perspective of SE is extremely 
difficult to do away with. Seidlhofer (2005), for example, maintains that the "Anglo-Saxon attitudes" (p. 167) are still extremely prevalent in English language education around the world. That is, while on the surface we have moved away from monocentrism, in reality pluricentrism is still to be materialized at various levels of English language teaching and learning. Seidlhofer (2005) calls this phenomenon "submission to native-speaker norms" (p. 170). This tendency of submission is so strong that in certain non-native contexts educators are establishing the so called "English village" in order to immerse nonnative English learners (Jenkins, 2006, p. 172) to approximate the native standards.

As one can see, ELT in the twenty-first century suffers from a lack of a uniform variety of English for instructional purposes. The discussions above illustrate how issues such as "standards" and "ownership" of English play significant roles in ELT today. The continuous spread of English has been a tremendous boost for the recognition of nonnative varieties of English as viable alternatives to innercircle English for ELT. In spite of a considerable amount of work in this regard, it seems as though it is going to take a while before such a pluricentric approach to English becomes the norm rather than exception in ELT.

\section{Issues of curriculum and materials}

While setting a uniform target variety is important for English language instruction, designing effective curricula (although there are disagreements, I use the term syllabus and curriculum interchangeably in this paper, see Brown, 1995 for more) and developing suitable materials are also part of important considerations in ELT. With an everexpanding landscape of English, ELT curriculum and materials need to be innovative to meet the burgeoning complexities surrounding English language pedagogy. Below, I discuss why it is often difficult to make ELT curriculum and materials effective while facing the challenges that various WE phenomena pose.

Innovation and flexibility are two major themes in the twenty-first century to deal with the new challenges one encounters on a daily basis. Like other spheres of life, this phenomenon is applicable in ELT as well. Likewise, it is important to consider the adaptability factors in ELT-factors that would make various aspects of ELT — curriculum and materials, methods and approaches serve the desired purposes most efficiently. The ensuing discussions will show this task is not easy. Hadley (1999) reports on novelty in ELT curricula at the tertiary level in some Japanese colleges and universities. To keep up with the need for effective English language pedagogy and at the discretion of the Japanese Ministry of Education, these colleges and universities introduced what Hadley describes as "innovative" ELT curricula. Some of the characteristics of these curricula are: only English language usage in classrooms (also known as immersion), no teacher-centered classes-students may express themselves the way they wanted-"laughing, joking, and expressing their opinions in English" (Fukuda \& Sasaki, 1995; cited in Hadley, 1999, p. 93). Also prevalent were practices such as "English lounges" where English was the only language for communication, nativespeaker-conducted English classes, pairing students with native-English-speaking roommates (e.g., American), and increasing the number of native-speaking teachers to promote co-operative learning based on interactions between teachers and learners. Furthermore, English content courses taught exclusively in English were introduced.

As one examines the characteristics of "innovative" ELT curricula, several interesting phenomena emerge. Clearly, making learners communicatively competent is an objective that was taken seriously by administrators at these institutions. Furthermore, there is an attempt to provide learners with as much exposure to English as possible, by creating English-speaking environments within a non-native context. In fact, there are overt efforts to have native-speaking teachers/students involved in the process (which may remind one of the "Anglo-Saxon attitudes" [Seidlhofer, 2005, p. 167] of grassroots-level administrators). While it is heartening to see efforts for innovation in ELT, one cannot help wondering about potential challenges associated with it. For instance, implementing the mandatory use of English at all times may help improve learners' spoken abilities, but the question 
remains as to how an instructor may objectively write and give a test on such open-ended skills acquired by learners. How about learners' reading and writing skills-do the administrators consider them entirely irrelevant to learners for effective communication in English? Having as many native-speaking teachers as possible may sound exciting, but is it not, in essence, reverting to the old days of approximating native varieties of English, and thus undermining the "World Englishes movement"? Issues such as these continue to baffle ELT circles far and wide.

Drawing on the "functional" dimensions of language use, Coffin (2003) recommends that curriculum designers/language teachers organize and structure the language curriculum in ways that would fall in line with the "theory of language as "social action"' (p. 11). She identifies four areas of language use on which learners need to build their knowledge, namely, text structure, experiential, interpersonal, and textual grammar. Each of these four areas serves various aspects of language use in everyday life. Knowledge of text structure, for example, would help learners with different types of written and spoken texts in different cultures and contexts. Knowledge of experiential grammar provides learners with "grammatical resources for representing the world" (p.15)—making them aware of the people or things, processes, and circumstances involved in language use. And, while interpersonal grammar relates to knowledge of successful incorporation of linguistic choices based on various social relations and attitudes, textual grammar helps learners organize the message so as to facilitate the smooth "flow of information" (Coffin, 2003).

Coffin (2003) argues that a careful and systematic analysis of these four areas of language use can provide important insights into devising syllabuses for English language learners. What is interesting in Coffin's (2003) argument is that she proposes the identification of a set of spoken and written genres that directly relate to the social and cultural contexts in which language learners are most likely to operate. These genres then could be incorporated into the language syllabus. While Coffin's (2003) acknowledgement of social and cultural sensitivity renders support to the pluricentrism that is central to the discussion of a World Englishes perspective of
ELT, there are potential shortcomings to her notion of ELT syllabus. English education in the twenty-first century has crossed all national borders. Therefore, it is extremely difficult to devise a localized, contextspecific syllabus that would address all possible social and cultural contexts in which English learners would operate. Also, for the most part, the major theme of ELT in our time is to acquire communicative competence. Having students learn a handful of spoken and written genres would certainly not serve them well to this end.

Adding second language acquisition perspectives to the current discussions on ELT, Ellis (1993) argues for structural syllabuses in English language programs. Structural syllabuses would incorporate structures of the language at various levels (e.g., phonology, morphology, syntax) for English language learners. The rationale behind Ellis' argument rests upon the claim that grammar teaching should be done as part of "consciousnessraising" act among learners. In short, consciousnessraising refers to instilling an understanding of the various "formal and functional properties" of the target language in learners' minds. This process of consciousness-raising is compatible with L2 acquisition theory of "learnability" (Ellis, 1993). While Ellis' (1993) accounts add interesting L2 acquisition perspectives to ELT syllabus design, it must be remembered that there have been longdrawn debates regarding whether or not grammar instruction helps language learning in the first place (e.g., Ferris, 1999; Truscott, 1996). Furthermore, much of English language learning in the twentyfirst century occurs in informal, out-of-class settings and learners are generally exposed to a myriad of language input, derived from different varieties of English in various contexts. Therefore, ELT syllabuses that do not account for contextual variables such as these may turn out to be ineffective.

As research aims to reach a common ground for intelligibility of different varieties of English across the world, Jenkins (1998) presents some core phonological issues to be included in the pronunciation syllabus of English language programs. Jenkins (1998) identifies problems with setting the unrealistic goal of approximating native speakers (e.g., either British or American) norms in the syllabus. Instead, she argues 
for a compromise norm of pronunciation of English as an International Language (EIL). EIL norms would have three core areas of instruction namely segmental, nuclear stress, and the effective use of articulatory setting. Jenkins (1998) maintains that EIL norms of pronunciation would promote international intelligibility, freedom to express EIL speakers' own variety, and stop approximation of native speakers' norms. Jenkins' (1998) argument, while persuasive, it is just a proposal and likewise, we must examine it carefully. As one would imagine, codifying all pronunciation problems with non-native speakers of English is an extremely difficult task. Also, it is quite daunting to address pronunciation difficulties of nonnative speakers with so many different L1s and to come up with a uniform set of core pronunciation instruction areas. All in all, one may see that designing an effective English curriculum entails a great deal of difficulty.

Since curriculum design and materials development go hand in hand, failing to shed some light on materials development, this section of the paper would remain incomplete. Good materials are essential for achieving the goals and objectives stated in the syllabus. Lately, the concept of authentic texts (Little, Devitt, \& Singleton, 1988) is quite pervasive in ELT circles. It is believed that “...exposing students to the language of the real world will help them acquire an effective receptive competence in the target language" (Guariento \& Morley, 2001, p. 347). It is also believed that authentic texts bridge the gap between students' linguistic knowledge and their capacity to use the language in real life situation (Wilkins, 1976 as cited in Guariento \& Morley, 2001). Literature in the field suggests that, in spite of their supposed effectiveness, authentic texts/materials are not devoid of their own share of problems. One of the problems voiced by Guariento and Morley (2001) is the mismatch between authentic texts and language tasks. They argue that authentic materials are of no help unless they can derive authentic responses from language learners.

This phenomenon is especially true in the case of English language materials. In ELT, for example, learners' tasks are typically based upon guessing rather than a complete control and understanding of the tasks as students cannot relate the tasks to the contexts (i.e., materials used come from contexts such as USA or Britain that are completely foreign to them). The claim that authentic materials stimulate motivation in language tasks also needs to be considered with caution. Peacock (1997) shows how authentic materials were found less interesting than artificial materials. On a separate note, Wong, Kwok, and Choi (1995) maintain that the effectiveness of authentic materials depends upon, among other things, teacher's knowledge of "each student's ability," students' "temperament and readiness," and the teacher's judgment on manipulation of the materials. González (2010), in this regard, argues for an incorporation of local teacher educators' voices into the design of curricula and development of materials.

As one can see, materials by themselves cannot involve students in tasks for language learning. It requires a great deal of perseverance and hard work on the part of the teachers. In fact, without teachers' conscientious efforts, it is extremely difficult for language learners to make the best use of the materials. The bottom line is that unless more localized culture- and context-specific materials are used in ELT classrooms, it is difficult for both teachers and learners to relate to the language tasks. Matsuda (2003) fittingly argues that textbooks should provide English language learners more exposure to English as an International Language (EIL) by incorporating more characters from outer- and expanding-circle countries. In order for a successful incorporation of EIL components into the materials, textbook writers/ materials developers must be conscientious of the appropriacy of the characters and activities/tasks so that they derive "authentic" response from learners.

\section{What to test, how to test?}

Tests are integral part of any language program. No matter how undesirable tests are, for both teachers and learners, there needs to be some form of tests in order for teachers to assess learners' achievement and to evaluate the effectiveness of instructions. Furthermore, tests may be required for gate-keeping measures for various purposes (e.g., jobs, immigration, pay raise, etc.). More often than not, language tests entail high-stakes choices. Tests 
in ELT are particularly complicated, at least on two counts: First, there are an unprecedented number of test takers (more generally, "users," which include both test givers and test takers, and all others who use test scores for some reasons) of English and the stakes involved in these tests are enormous. Second, as mentioned earlier, there is no single reference point for SE, making both teachers and learners grapple with the design and preparation for these tests. It is the latter that relates more directly to various WE phenomena. Because there is no uniform reference point for SE, it is difficult for test givers to design and administer tests that would truly test learners' knowledge for communication in the pluricentric world. Furthermore, although there are various local varieties of English, they are invariably excluded from most high-stakes proficiency tests in English. At the local level, too, teachers are compounded by questions such as how to test learners' proficiency in English objectively and what skills reflect learners' actual proficiency.

Hamp-Lyons and Davies (2008) maintain that high-stakes English proficiency tests such as TOEFL and IELTS are often condemned on the grounds that they are biased and unfair to test takers who follow exonormative standards. The contention revolves around the fact that while an International English (IE) view of the situation suggests that there is and should be only one norm of English, the norm of the educated native speakers of English, the more liberal of WE is that to impose an IE norm on nonnative English speakers, many of whom already have local standards/norms (such as Singaporean English, Indian English), is discriminatory (HampLyons \& Davies 2008).

Additionally, though high-stakes proficiency tests of English such as IELTS, TOEFL, TOEIC, etc. are often claimed to be international in their scope of potential test takers and the varieties of English tested, Chalhoub-Deville and Wigglesworth (2005) express their reservations about such claims. While it is true that IELTS has international partnership (i.e., University of Cambridge, The British Council, and IDP Australia) for developing tests, it still fails to provide a uniform reference point as to what should be considered as an international knowledge base for English (Chalhoub-Deville \& Wigglesworth,
2005). The same is true about TOEFL. For instance, although TOEFL's purpose statement endorses the use of the TOEFL scores by various institutions such as government agencies around the world, its research agenda and test design and development do not support the incorporation of such uses of English (Chalhoub-Deville $\&$ Wigglesworth, 2005). Test of Spoken English (TSE), a component of TOEFL, supposedly measures test takers' proficiency in communicating in English. However, Chalhoub-Deville and Wigglesworth (2005) maintain that the "design, development, and research... [are] ...oriented by and focused on North American contexts" (p. 386), ignoring the vast majority of other contexts around the world in which the test results are to be used.

High-stakes proficiency tests aside, localized English tests too are compounded by various phenomena of WE, for the most part, by the fact that there are so many varieties and norms of English. As a result, while writing tests, local test administrators fail to set the appropriate target model of English. Additionally, because there is no uniform variety of English to be used as a reference point, English language learners often go through enormous stress as well.

Another level of problem emerges when test givers have to decide what kind of proficiency is to be tested. Generally speaking, one's language proficiency entails a holistic measure of one's competence in the target language. However, in reality, especially after the inception of the communicative method of language teaching, English educators are caught-up between testing learners' communicative competence and discretepoint grammatical knowledge. In outer- and expanding-circle countries, it is still not certain whether it is enough to test learners' communicative competence as an appropriate measure for proficiency in English, since testing communicative competence by itself may not be able to provide a true indication of learners' writing and reading skills necessary for various academic and professional contexts. That is, someone who is communicatively competent in non-academic, informal situations may still have difficulty in reading and writing tasks at academic and professional levels. 
Conundrums relating to standards of English pose a different kind of problem in testing spoken English. As mentioned earlier, because there is no uniform reference point for SE pronunciation, it is extremely difficult for test administrators to set uniform grading rubrics for testing pronunciation. Although Levis' (2005) "intelligibility principle" may be considered to be a compromise position in assessing pronunciation, researchers argue that there is no universally-agreed-upon measure for "intelligibility" of speech (Derwing $\mathcal{E}$ Munro, 2005; Jenkins, 2000). In fact, there are so many variables that affect intelligibility measurement that it is almost impossible to obtain a truly objective score of intelligibility. Finally, most second language acquisition research shows that foreign accent is a natural phenomenon for post-puberty learners of any given language. Therefore, there are questions regarding whether or not it is practical to set nativelike pronunciation norms for testing spoken English.

As one can see, testing in ELT can be extremely difficult. It is evident from the discussions above that many of the problems occur due to the unavailability of a uniform, universally-agreed-upon standard variety of English that can be modeled while designing tests. Additionally, diverse global communication scenarios as well as new needs and new demands coupled with an ever-changing landscape of English language because of its continuous spread over the last few decades make it challenging for educators to determine English language testing norms. Needless to say, this continues to confound English language teachers in their classroom teaching and beyond.

\section{New age, new challenges, new roles of English teachers}

English teachers these days are confronted with unprecedented challenges that make their job difficult. Because teachers play a central role in language pedagogy both in and outside the classroom, the way they go about doing their tasks has a profound impact on ultimate teaching and learning outcomes. Literature in the field suggests how English teachers' jobs have become complex with the emerging norms and varieties of English across the globe. Additionally, English teachers have to work within various local exigencies, which keep changing across contexts and cultures and give rise to further challenges (e.g., Baumgartner, 2007). Overall, in order for English teachers to be successful in their job, it is imperative that they are aware of the various nuances of ELT at present. Matsuda (2006) amply maintains that changing curriculum alone does not help materialize the changes in ELT. Since teachers play a crucial role in carrying out the actual teaching activities, teacher training is an important process that must be given due importance.

Non-native English-speaking teachers (NNESTs) constitute about 80 percent of the total English teachers in the world (Canagarajah, 1999). Considering the current status of English language education, it is neither practical nor possible to employ only native English-speaking teachers (NESTs) to teach English (Pasternak \& Bailey, 2004). What this means is that NNESTs need to be properly trained and educated with the current theories of language and methods of language teaching. In addition, they must also be abreast of the latest language acquisition theories so that they can employ the requisite knowledge of ELT.

This brings us to the core issue of teacher education: How are language proficiency and professional qualifications viewed in ELT? It is indeed an intriguing issue that has left scholars in the field occupied in debate for years. Pasternak and Bailey's (2004) view on the matter is that language proficiency is only one aspect of English language teachers' professional qualification. English teachers must also have appropriate professional preparations to be able to teach (Phillipson, 1992). They must have declarative knowledge-knowledge about the subject area, in this case the English language, as well as an understanding of various facts relating to educational psychology, second language acquisition, and current socio-political events. They must also have procedural knowledgeknowledge about how to/ability to do things, in this case the actual teaching. Pasternak and Bailey (2004) maintain that English language teachers should be able to accomplish at least three key things: Knowing about (1) how to use the target language; (2) how to teach in a culturally sensitive way; and (3) how to behave in a target culture (p. 158). As explained in 
Pasternak and Bailey's (2004) accounts, ELT in our times is much more complicated than many believe. English teachers need much more than just being native speakers of English. In fact, being native English speakers and having proficiency in English do not necessarily go hand in hand (Pasternak $\mathcal{E}$ Bailey, 2004). Furthermore, even if an English teacher is proficient in English, that alone does not qualify him or her to be a good teacher-he or she needs much more professional preparation to be eligible for teaching. This means that associating native English speakers with an automatic choice for English teaching positions is quite problematic since native English teachers may be completely foreign to various local needs and preferences.

Drawing on the examples of the teacher education programs in Egypt and Uzbekistan, Snow, Kamhi-Stein, and Brinton (2006) outline important points that need to be taken into consideration for both pre- and in-service English teacher training programs. They stress that "...the immediate context of language teaching and the socio-cultural factors..." (p. 274) should be important criteria while devising teacher training programs for English-as-alingua-franca settings. Indeed, contextual variables are too important to be ignored in teacher education curriculum since teachers have to work under various local constraints. Snow, Kamhi-Stein, and Brinton's (2006) further recommendations include going beyond the inner-circle variety of English both in teacher training programs and classroom teaching and deconstructing the myth of the native speaker. They also argue that while there can be collaboration between local and outside experts, professional development should be guided by local norms. González (2010), for example, shows how Columbian teachers and teacher educators are gaining "respected space" in ELT and "displacing some traditional voices of world-renowned scholars" (pp. 344-45).

Overall, literature in the field recognizes the importance of promoting local norms for the English language in teacher training programs. There is also enough indication for going beyond inner-circle varieties of English and training English teachers to value local varieties of the language (e.g., Snow, Kamhi-Stein, E Brinton, 2006). However, the fact remains that it is difficult to entirely do away with inner-circle-centric norms, partly because in many cases teacher education programs are either funded or administered by inner-circle English language educators (Snow, Kamhi-Stein, E Brinton, 2006). A corollary of this is that English teacher training objectives, materials, or even the training itself rarely addresses context-specific needs. In fact, inner-circle-centric ideologies are so profoundly embedded into the teacher training curricula that native-speaking norms are automatically transmitted into the training activities. Since there is still a lack of a well-laid-out and comprehensive nonnative-speaking English teacher training program, realistically it is going to take a lot of time before one can move beyond the inner-circle norms.

As with the three other areas I discussed previously, teacher training programs are heavily dependent upon inner-circle norms. Although literature abounds arguing for a pluricentric, allencompassing ELT approach that would recognize non-inner-circle varieties of English, the accounts above show that while we are well underway to that end, problems are still prevalent. In order to take ELT forward, both educators and theorists in the field must recognize these facts sooner than later.

\section{Discussions and implications}

So far in this paper I have problematized some of the contentious issues surrounding ELT from WE perspectives. My discussions looked at the difficulties in four major areas of concern, namely, setting a uniform standard variety for ELT, curriculum design and materials development, testing, and teacher training. Literature on these issues indicates that much work has already been done. However, one must say that ELT in the twenty-first century faces stiffer challenges than ever before. Tasks related to ELT are constantly confounded by the current trend of the global spread of English, emerging new stakes coupled with diverse, and at times, conflicting expectations of the various stakeholders. While it is extremely difficult to come to terms with the challenges that ELT faces, below I discuss what I consider to be a pragmatic and humanistic approach to ELT. 


\section{A pragmatic approach to $E L T$}

A pragmatic approach to ELT considers the "do-ability" issues in teaching and all relevant tasks. It is evident from the accounts above that ELT in our time is complex. Therefore, the most viable option for educators would be to first determine the "doability" criteria for ELT. An evaluation of the English language teaching goals against the do-ability factors would help teachers/administrators set more realistic targets for themselves.

So what would be the procedures for determining the do-ability criteria in ELT? How would an inventory of do-ability criteria help ELT practitioners better? How would such a move help re-conceptualize the priorities of ELT in the twentyfirst century and to what benefits? One can begin by considering Widdowson's (1994) accounts discussed earlier as a starting point. ELT practitioners should focus more on the communicative functions of English rather than its communal functions. That is, focus on communicative functions would allow the users of English, native and nonnative alike, to become more tolerant and respectful to each other (e.g., Bhatia, 2014), to accept the realities regarding the current status of the English language. That said, considering the vast landscape of English, finding a common ground for communication is understandably not easy. For instance, a huge majority of English language users would be concerned about the intelligibility and comprehensibility of English interlocutors' speech, communication failures, misunderstanding and/ or other potential scenarios thereof. However, as Canagarajah (2013) suggests, showing tolerance and respect to each other emanating from the realization of the current status of English can help enhance mutual understanding to a large extent. It would also help erase the myth of nonnative speakers' inability to communicate in English in challenging situations. In order for this to happen sustained communicative efforts (rather than communal propaganda) need to be enforced so that people become savvier about the intelligibility and comprehensibility of ELF and EIL. Promoting the communicative functions would also help break the jinx of native-nonnative dichotomy and broaden the perspectives on the users of English across the world.
A related and somewhat complementary measure to the above would be a complete abandonment of the "Anglo-Saxon attitudes" (Seidlhofer, 2005) up to the grassroots levels. This entails that more awareness and recognition of the enormity of the nonnative speaking population need to be firmly established. Although understandably an arduous task, this can be initiated by including the current status, and the statistics relating to the outer- and expanding-circle English in ELT materials all over the world. We can hope that knowledge of the current status of English would empower nonnative speakers by instilling confidence in them and helping generate more neutral attitudes toward speakers of English worldwide. Although the current efforts in the literature to describe English speakers from the outer- and expanding-circle as speakers of English as a lingua franca (ELF) or of English as an international language (EIL) provide alternative perspectives on the ongoing conundrums regarding the issue, these terms are by themselves discriminatory. Instead, a more pragmatic and meaningful approach would be to describe all English speakers within a single bracket as "English speakers," in which case, all English speakers would be known as "English speakers" only, without a string attached to them. It is only at this point that one can expect true change of attitudes towards and efforts for accommodation of all English speakers regardless of their L1 backgrounds.

A rather more obvious and less drastic measure would be to train English teachers within the latest language acquisition theories and perspectives on WE. Efficient English teachers are central to ELT; therefore, efforts must be made for educating English teachers with up-to-date theories of language. Furthermore, it must also be established that professional expertise is much more important than language proficiency. That is, proficiency in English alone does not qualify someone for an English teaching position (Phillipson, 1992, p.15). Teachers' professional expertise-knowledge about the subject area plus an understanding about various facts relating to educational psychology, second language acquisition, and current sociopolitical events as well as the ability to deliver the knowledge should be the sole criteria for determining professional expertise. Local norms for professional 
development as well as more universal standards must be incorporated in teacher training.

A pragmatic approach to ELT in line with the accounts above is necessary in order for making English language pedagogy more accessible and viable. It is imperative that the practitioners in the field shake off all limiting factors in order for ELT to assume a more progressive agenda to take the English language teaching and learning movement forward. Eliminating all barriers and embracing diversities should be the driving principles for ELT to sustain its growth and vitality in the twentyfirst century.

\section{A humanistic approach to $E L T$}

The concept of a humanistic approach has been part of educational theories and practices for a long time. The efficacy of such an approach lies in explaining some of the problems relating to ELT raised in this paper. I adapt renowned educational theorist Nimrod Aloni's (1997) notions on humanistic education in my attempt to delineate a humanistic approach to ELT. According to Aloni, a humanistic approach to education must be committed:

...to the enhancement of human freedom and growth, to the realization and perfection of human potentialities, and to an ethical code that places the highest value on the dignity of humanity, as an end in itself, in relation to which all political, religious, economic, and ideological doctrines are regarded as means to its enhancement. (p. 96)

Taking Aloni's (1997) accounts as a departure point, I suggest that a humanistic approach to ELT relate to considerations about setting goals and assigning tasks in ELT that are "humanly" possible. Such ELT goals and tasks must help the "realization and perfection of human potentialities" (Aloni, 1997, p. 96) rather than acting as political, economic, and ideological means to subjugate English learners. Literature in the field suggests that English language teaching/learning has traditionally targeted nativelike proficiency. However, apart from its underlying political and ideological ramifications, setting such a target is problematic on at least two counts: First, it is clear from the discussions in this paper that there is no universally-accepted single reference point for SE. Second, research shows that it is extremely difficult, if not impossible, especially for post-puberty language learners, to achieve nativelike proficiency (e.g., Derwing $\&$ Munro, 2005). Why should ELT course goals and objectives then persist with an elusive "native-likeness," approximating proficiencies that are ostensibly impossible to achieve while leaving out more viable alternatives for acquiring communicative competence? Aloni's humanistic education views learning to be "the properly human way of developing natural talents and capacities" (Gadamer, 1975, p. 11, as cited in Aloni, 1997).

In this connection, one may consider the example of the high-stakes English proficiency tests. Although TOEFL and IELTS scores are widely used as standard measures for proficiency in English, for the most part these tests are designed to measure either American or British norms of English. While it is well-accepted that the bulk of the communication in English in today's world occurs among nonnative English speakers, to what extent these tests are justifiable for measuring English proficiency remains a contentious issue (Canagarajah, 2006). A poignant direct effect of this on test takers is that they attempt to approximate the native speakers' norms (primarily to pass these tests), knowing that in real life situations they are more likely to communicate with nonnative speakers of English. What is more, definitions of the terms such as "native-likeness" or "nativeness" themselves are relative to contexts as they vary even within native-speaking societies, and that there is no uniform measure for native-likeness and nativeness (Levis, 2005). A humanistic approach that aligns with the terms and definitions stated above rejects such objectives of ELT on the ground that they are devoid of "self-generation, self-nourishment, and self-creation" (Aloni, 1997, p.102). The most logical goal for ELT courses should be such that English learning helps learners communicate successfullythat is, the learners are able to accomplish "the ideational, the interpersonal, and the textual functions" (Berns, 1990, p. 104) in English.

Furthermore, a blind approximation of nativelike proficiency or a specific standard for English language teaching and learning denounces the 
fundamental human spirits that crave the values and ideologies specific to the native culture (Canagarajah, 1999). González (2010) reports how the adoption of the Common European Framework of Reference (CEFR) as the standard in English language education policy in Colombia encountered resistance from students and teachers alike. A humanistic approach to ELT would promote sensitivities towards learners' native cultures, and "self-regulated development [and] spontaneous ... exercise of natural powers" (Aloni, 1997, p. 92). Such an approach would also help both teachers and learners appreciate diversity and pluricentrism-two central characteristics of WE. After all, considering the current landscape of English, no one can confine his or her perspectives to the native-speaking norms of English anymore.

Finally, if the purpose of having nativespeaking norms of English is "exclusion" rather than "inclusion" (Widdowson, 1994), such a purpose is completely uncalled for given the current sociopolitical scenarios. A pluricentric approach to English is what the world needs most, whereby diversity would stand for a welcome change, not as a basis for discrimination, intended or unintended. Only a humanistic approach to ELT can ensure an end to this effect.

\section{Conclusion}

I must concede that ELT in our time is much more complex than a framework of the kind proposed here can resolve. There are issues that are difficult to deal with as the ever-changing landscape of English comes up with fresh challenges. For instance, people all over the world learn English for a variety of purposes, with a whole range of goals and objectives in mind. Likewise, designing a uniform needs analysis framework, curriculum, appropriate teaching methodology, and assessment tools for this entire spectrum of the population is almost an impossible task. Nevertheless, future research in the field may delve into issues such as what gatekeeping systems are prevalent (and appropriate) in the contexts of nonnative-nonnative communication (e.g., in a context where a nonEnglish-speaking student seeks admission to a non-
English-speaking high school/college/university), to what extent the prevalent high-stakes English tests are successful in providing reliable measures for the diverse communication needs for English language learners given the changing landscape of the English language, and whether a preference for native English teachers is customary only at college or university levels or whether it pervades $\mathrm{K}$ through 12 education as well. Furthermore, it would be interesting to explore to what extent nonnative speakers of English are willing to accommodate their native-speaking counterparts to facilitate communication, for communication is a mutual act, and successful communication is not only a native speakers' burden, after all. This entails that in order for successful communication to take place nonnative speakers of English must learn how to accommodate their native-speaking counterparts in ways that would enhance mutual intelligibility. In order for a more comprehensive understanding of ELT, future research must look into issues such as these.

To conclude, in this paper I attempted to point out various mismatches in English language teaching goals and objectives vis-à-vis teaching and learning outcomes in four major areas of concern-I discussed how setting standards for the target variety of English for instruction purposes, designing curriculum and developing materials, testing, and training teachers have become complicated due to the global spread of English. Although chosen somewhat arbitrarily, these four areas constitute the major components of any language education program. It is hoped that delineating these issues may instill useful insights into the rich body of literature and research in ELT. I must also acknowledge at this point that my plea for a pragmatic and humanistic approach to ELT is derived partly from the predicament English language learners around the world face due to various WE phenomena described here and partly from my personal experience as a nonnative speaker of English. Although some of the issues discussed in this paper can be found elsewhere, especially publications relating to WE, my efforts here have been intended to make ELT practitioners aware of the current challenges they face because of the global spread of English. I argue that in order for 
English language learners to become successful, ELT must promote pluricentrism as its core and diversity of English in the real sense of the term to do away with the so-called native-speaking norms for SE.

\section{References}

Aloni, N. (1997). A redefinition of liberal and humanistic education. International Review of Education, 43, 87-107.

Alptekin, C. (2002). Towards intercultural communicative competence in ELT. ELT Journal, 56, 57-64.

Baumgartner, R. (2007). Teaching world Englishes. In B. B. Kachru, Y. Kachru, \& C. L. Nelson (Eds.), Handbook of world Englishes (pp. 661-679). Oxford, UK: Blackwell.

Berns, M. (1990). Contexts of competence: Social and cultural considerations in communicative language teaching. New York: Plenum Press.

Bhatia, T. K. (2014). Review of translingual practice: Global Englishes and cosmopolitan relations. World Englishes, 33, 294-297.

Blommaert, J., \& Verschueren, J. (Eds.). (1991). The pragmatics of international and intercultural communication. Amsterdam: Benjamins.

Brown, J. D. (1995). Elements of language curriculum: A systematic approach to program

development. Boston, MA: Heinle.

Brutt-Griffler, J. (2002). World English: A study of its development. Clevedon, UK: Multilingual Matters.

Canagarajah, S. A. (1999). Resisting linguistic imperialism in English teaching. Oxford, UK: Oxford University Press.

Canagarajah, S. A. (2006). Changing communicative needs, revised assessment objectives: Testing English as an international language. Language Assessment Quarterly, 3, 229-242.

Canagarajah, S. A. (2013). Translingual practice: Global Englishes and cosmopolitan relations. New York: Routledge.

Chalhoub-Deville, M., \& Wigglesworth, G. (2005). Rater judgment and English language speaking proficiency. World Englishes, 24, 383-391.

Coffin, C. (2003). Exploring different dimensions of language use. ELT Journal, 57, 11-18.
Crystal, D. (1997). English as a global language. Cambridge, UK: Cambridge University Press.

Derwing, T., \& Munro, M. (2005). Second language accent and pronunciation teaching: A research based approach. TESOL Quarterly, 39, 379-397.

Ellis, R. (1993). The structural syllabus and second language acquisition. TESOL Quarterly, 27, 91-113.

Fukuda, K., \& Sasaki, M. (1995). Immersion program ni kanren suru shisatsu hokoku [Task group report on immersion programs]. Paper presented at the Niigata University General Education and Language Group, Niigata City, Japan.

Ferris, D. (1999). The case against grammar correction in L2 writing classes: A response to Truscott (1996). Journal of Second Language Writing, 8, 1-11.

Gadamer, H. G. (1975). Truth and method. New York: Crossroad.

González, A. (2010). English and English teaching in Colombia: Tensions and possibilities in the expanding circle. In A. Kirkpatrick (Ed.), The Routledge Handbook of World Englishes (pp. 332-351). New York: Routledge.

Graddol, D. (1997). The future of English. London: The British Council.

Graddol, D. (1999). The decline of the native speaker. AILA Review, 13, 57-68.

Guariento, W., \& Morley, J. (2001). Text and task authenticity in the EFL classroom. ELT Journal, 55, 347-353.

Hadley, G. S. (1999). Innovative curricula in tertiary ELT: A Japanese case study. ELT Journal, 53, 92-99.

Hamp-Lyons, L., \& Davies, A. (2008). The Englishes of English tests: Bias revisited. World Englishes, 27, 2639.

Jenkins, J. (1998). Which pronunciation norms and models for English as an international language? ELT Journal, 52, 119-126.

Jenkins, J. (2000). The phonology of English as an international language: New models, new norms, new goals. Oxford, UK: Oxford University Press.

Jenkins, J. (2002). A sociolinguistically based, empirically researched pronunciation syllabus for English as an international language. Applied Linguistics, 23, 83103.

Jenkins, J. (2006). Current perspectives on teaching world Englishes and English as a lingua franca. TESOL Quarterly, 40,157-181. 
Kachru, B. B. (Ed.). (1982). The other tongue: English across cultures. Urbana, IL: University of Illinois Press.

Kachru, B. B. (1985). Standards, codification and sociolinguistic realism: The English language in the outer circle. In R. Quirk \& H. G. Widdowson (Eds.), English in the world (pp. 11-30). Cambridge, UK: Cambridge University Press.

Kachru, B. B., \& Nelson, C. L. (1996). World Englishes. In S. L. McKay \& N. Hornberger (Eds.), Sociolinguistics and language teaching (pp. 71-102). Cambridge, UK: Cambridge University Press.

Kirkpatrick, A. (2007). World Englishes: Implications for international communication and English language teaching. Cambridge, UK: Cambridge University Press.

Levis, J. (2005). Changing contexts and shifting paradigms of pronunciation teaching. TESOL Quarterly, 39, 369-377.

Little, D., Devitt, S., \& Singleton, D. (1988). Authentic texts in foreign language teaching: Theory and practice. Dublin: Authentik.

Lowenberg, P. H. (2000). Non-native varieties and the sociopolitics of English proficiency assessment. In J.K. Hall \& W. G. Eggington (Eds.), The sociopolitics of English language teaching (pp. 67-82). Clevedon, UK: Multilingual Matters.

Matsuda, A. (2003). Incorporating world Englishes in teaching English as an international language. TESOL Quarterly, 37, 719-729.

Matsuda, A. (2006). Negotiating ELT assumptions in EIL classrooms. In J. Edge (Ed.), (Re) locating TESOL in an age of empire (pp. 158-170). Hampshire, UK: Palgrave Macmillan.

Pasternak, M., \& Bailey, K. M. (2004). Preparing nonnative and native English-speaking teachers: Issues of professionalism and proficiency. In L. D. KamhiStein (Ed.), Learning and teaching from experience: Perspectives on nonnative English-speaking professional (pp. 155-175). Ann Arbor: University of Michigan Press.
Peacock, M. (1997). The effect of authentic materials on the motivation of EFL learners. ELT Journal, 51, 144-156.

Phillipson, R. (1992). ELT: The native speaker's burden? ELT Journal, 46, 12-18.

Rajagopalan, K. (2004). The concept of "World English" and its implications for ELT. ELT Journal, 58, 111117.

Seidlhofer, B. (2002). Habeas corpus and divide et impera: "Global English" and applied linguistics. In K. Spelman Miller \& P. Thompson (Eds.), Unity and diversity in language use (pp. 198-217). London: Continuum.

Seidlhofer, B. (2004). Research perspectives on teaching English as a lingua franca. Annual Review of Applied Linguistics, 24, 209-239.

Seidlhofer, B. (2005). Standard future of half-baked quackery? In C. Gnutzmann E F. Intemann (Eds.), The globalization of English and the English language classroom (pp. 159-173). Tübingen, Germany: Narr.

Snow, M. A., Kamhi-Stein, L. D., E Brinton, D. M. (2006). Teacher training for English as a lingua franca. Annual Review of Applied Linguistics, 26, 261-281.

Spencer-Oatey, H. (Ed.). (2000). Culturally speaking. London: Continuum.

Strevens, P. (1983). What is "Standard English"? In L. Smith (Ed.), Readings in English as an international language (pp. 87-93). Oxford, UK: Pergamon.

Tripathi, P. D. (1998). Redefining Kachru's "Outer Circle" of English. English Today, 14, 55-58.

Truscott, J. (1996). The case against grammar correction in L2 writing classes. Language Learning, 46, 327369.

Widdowson, H. G. (1994). The ownership of English. TESOL Quarterly, 28, 377-389.

Wilkins, D. (1976). Notional syllabuses. Oxford: Oxford University Press.

Wong, V., Kwok, P., \& Choi, N. (1995). The use of authentic materials at tertiary level. ELT Journal, 49, 318-322. 